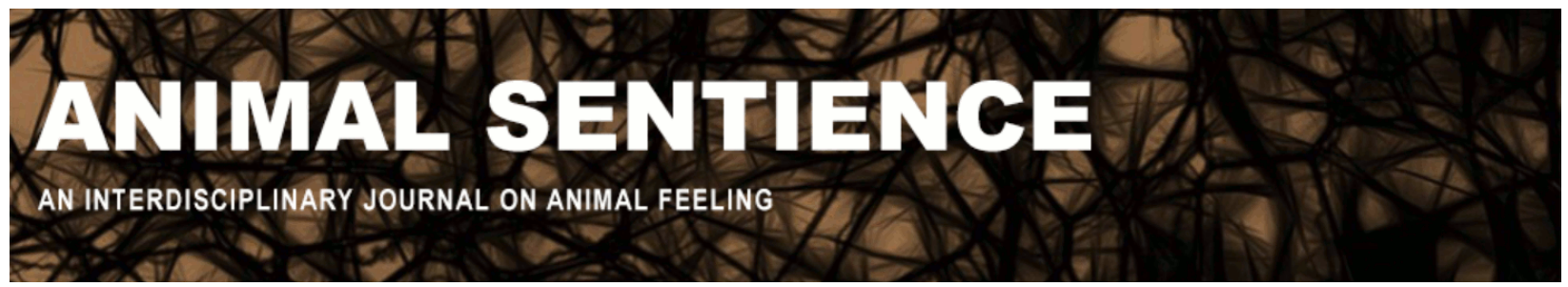

Brooks Pribac, Teya (2019) Positive sentience is underrated. Animal Sentience 25(11)

DOI: $10.51291 / 2377-7478.1445$

Date of submission: 2019-05-14

Date of acceptance: 2019-05-20

(c)

This article has appeared in the journal Animal

Sentience, a peer-reviewed journal on animal

cognition and feeling. It has been made open access,

free for all, by WellBeing International and deposited

in the WBI Studies Repository. For more information,

please contact

wbisr-info@wellbeingintl.org.

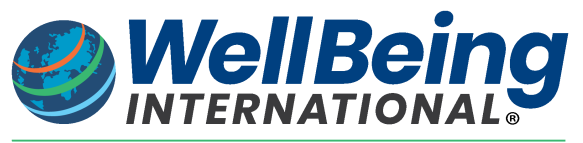

SOLUTIONS FOR PEOPLE, ANIMALS AND ENVIRONMENT 


\section{Positive sentience is underrated}

Commentary on Marino \& Merskin on Sheep Complexity

\section{Teya Brooks Pribac}

Arcohab, Australia

Abstract: My commentary focuses on two aspects of ovine (well-)being considered in the review: the developmental context and (un)fulfilled potentialities.

Teya Brooks Pribac holds a PhD
in animal grief from the
University of Sydney. She works
in animal advocacy and care
between Australia and Europe.
Website

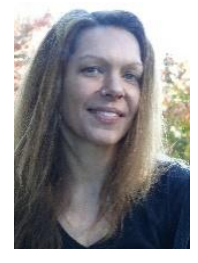

I have been following with great interest and appreciation Dr. Marino and colleagues' articles on farm animals over the past few years. The sheep review (Marino \& Merskin 2019) (M\&M) is another necessary reminder of the ubiquitous violence routinely inflicted upon sheep and other farm animals, a violence which extends well beyond the more commonly discussed physical pain. My commentary focuses on two aspects of ovine (well-)being considered in the review: the developmental context and (un)fulfilled potentialities.

Myron A. Hofer (1984) wrote that '[o]ne of John Bowlby's great contributions has been to place attachment and loss in the perspectives of development and evolution' (p. 183). For many researchers over the past half century, this has meant that they could study attachment and separation/loss in more or less invasive experiments on nonhuman animals and apply the findings to humans. As has been shown over and over again, including for sheep as some of the works cited by M\&M attest (e.g., Napolitano et al. 2008), attachment relations and the quality of the early social environment have important psychobiological value that goes beyond food acquisition and physical protection. Acting as a 'superstructure' (Polan \& Hofer 2016; see also Bradshaw \& Schore 2007), the caregiver and the dynamics of early social exchanges influence the young animal's organization internally (endocrine and immune functioning, levels of anxiety, etc.) and in relation to the outside world (e.g., social competencies), affecting the animals' short- and long-term well-being. It is time we cease considering nonhuman animals as mere 'models'. We must accept that, just like humans, other animals feel very deeply, and that once certain internal patterns are established, they are very difficult to modify (if nonhuman animals are given such a chance at all). Speaking from forty years of experience, rescuer and activist Patty Mark (2014) observed:

It may be easier to understand the extent of the violence and deprivation animals face within the industry when you look at these same animals in a sanctuary setting after they've been rescued. The damage becomes much more obvious when they are at last allowed autonomy; when they are given the freedom, for example, to not be touched by a human (pp. 106-107). 
Given the freedom to act and be sentient beings, sheep at last learn the joy of exploring their physical and social environments as well as their own internal landscapes. M\&M highlight sheep's capacity for emotional reactions to learning, a phenomenon l've witnessed many times. While my sheep community may not be representative of other sheep communities (Brooks 2019), it is safe to assume that its members are the best representatives of themselves as individuals. They have many favorite activities, one of which is standing on their hind legs trying to reach high-lying branches, and competing as to who can stand up longer and reach higher. Henry, one of the sheep, has never mastered the technique; I have never even seen him trying. Instead, he developed his own self-challenging exercise, which requires a substantial amount of patience. Nutritionally and gastronomically (favorite types of food), it is hardly worth the effort, but Henry seems to thoroughly enjoy it. Focusing principally on the rose bush, Henry first identifies a branch that is too high to eat from directly but low enough for him to grab with his mouth. Working very slowly and carefully, Henry releases the branch from his mouth and slips it under his chin. This is the trickiest part; the branch sometimes bounces back and Henry has to start all over again. With the branch under his chin, Henry moves his head very carefully to the side, lying his cheek on top of the branch. The branch is now held down by the cheek and the neck. Slowly, Henry moves towards the tip of the branch eating the leaves and petals along the way.

A creative, problem-solving mind may be a useless trait for a sheep stuck in a pen or barren paddock where all decisions are made for her whether she likes it or not. Nevertheless, just as in the case of physical or social pain and pleasures, when a mind's potential is there, the intellectual deprivation typical of agricultural settings becomes a very relevant ethical matter. Our recent more integrated understanding of nonhuman animals' individuality and relations reveals that the extent of their suffering is even greater than previously believed. Let us hope that this understanding, coupled with a greater appreciation of the cognitive bias that has brought us to the present state of affairs, will also inspire change.

\section{References}

Bradshaw, G.A., \& Schore, A.N. (2007). How elephants are opening doors: developmental neuroethology, attachment and social context. Ethology, 113(5), 426-436.

Brooks, D. (2019). The Grass Library. Blackheath: Brandl \& Schlessinger.

Hofer, M.A. (1984). Relationships as regulators: a psychobiological perspective on bereavement. Psychosomatic Medicine, 46(3), 183-197.

Marino, L., \& Merskin, D. (2019). Intelligence, complexity, and individuality in sheep. Animal Sentience 25(1).

Mark, P. (2014). Dreams and beyond. Southerly, 74(3), 102-116.

Napolitano, F., De Rosa, G., \& Sevi, A. (2008). Welfare implications of artificial rearing and early weaning in sheep. Applied Animal Behaviour Science, 110(1/2), 58-72.

Polan, H.J., \& Hofer, M.A. (2016). Psychobiological origins of infant attachment and its role in development. In: Cassidy, J., \& Shaver, P.R. (eds.), Handbook of Attachment: Theory, Research, and Clinical Applications, $3^{\text {rd }}$ edition. New York: The Guilford Press, pp. 117-132. 